\title{
Correction to: Severe hypoglycemia caused by a small dose of repaglinide and concurrent use of nilotinib and febuxostat in a patient with type 2 diabetes
}

Hitomi Komatsu ${ }^{1} \cdot$ Mariko Enomoto $^{1} \cdot$ Hisashi Shiraishi ${ }^{1} \cdot$ Yasuyo Morita $^{1} \cdot$ Daisuke Hashimoto $^{2}$. Shuichi Nakayama ${ }^{2}$. Shogo Funakoshi ${ }^{2} \cdot$ Seiki Hirano $^{2}$. Yoshio Terada ${ }^{2} \cdot$ Mitsuhiko Miyamura $^{1}$ - Shimpei Fujimoto ${ }^{2}$

Published online: 23 April 2020

(C) The Japan Diabetes Society 2020

Correction to: Diabetology International

https://doi.org/10.1007/s13340-020-00434-w

In the original publication, the unit of C-peptide immunoreactivity (CPR) in Table 1 was published incorrectly. The correct unit is $\mathrm{ng} / \mathrm{ml}$.

Publisher's Note Springer Nature remains neutral with regard to jurisdictional claims in published maps and institutional affiliations.

The original article can be found online at https://doi.org/10.1007/ s13340-020-00434-w.

Shimpei Fujimoto

fujimoto@kochi-u.ac.jp

1 Department of Pharmacy, Kochi Medical School Hospital,

Nankoku, Japan

2 Department of Endocrinology, Metabolism, and Nephrology,

Kochi Medical School, Kochi University, Kohasu, Oko-cho,

Nankoku, Kochi 783-8505, Japan 